\title{
SMR
}

\section{Sampling strategies for natural Toona ciliata populations}

J. Liu and J.M. Jiang

Research Institute of Subtropical Forestry, Chinese Academy of Forestry, Fuyang, China

Corresponding author: J.M. Jiang

E-mail: jiang_jingmin@163.com

Genet. Mol. Res. 15 (4): gmr15047751

Received March 29, 2016

Accepted June 6, 2016

Published October 17, 2016

DOI http://dx.doi.org/10.4238/gmr15047751

Copyright $(2016$ The Authors. This is an open-access article distributed under the terms of the Creative Commons Attribution ShareAlike (CC BY-SA) 4.0 License.

ABSTRACT. The genetic diversity and spatial autocorrelation of Toona ciliata populations were analyzed with eight microsatellite markers to determine an appropriate sampling strategy for the effective conservation of natural T. ciliata populations. The average number of alleles and effective number of alleles were 6.1 and 2.7, respectively. The mean expected heterozygosity was 0.6006 . Overall, $96.6 \%$ of the genetic variation existed in two natural populations, which was concluded from the coefficient of genetic differentiation $\left(F_{\mathrm{ST}}=0.1854\right)$. Therefore, two natural populations were selected for conservation and sampling. The mean effective number of alleles and expected heterozygosity increased with increasing sample number. The mean expected heterozygosity tended to be stable when the sampling number exceeded 30 . The maximum value of expected heterozygosity was 0.4770 when the sampling number was 45 . Therefore, 45 sampled individuals were sufficient for conservation and sampling. Similarity relationships existed between individuals within $240 \mathrm{~m}$. There were marked differences among individuals over $240 \mathrm{~m}$ away. The distance

Genetics and Molecular Research 15 (4): gmr15047751 
between individuals exceeded $240 \mathrm{~m}$ when natural populations were sampled.

Key words: Toona ciliata; Genetic diversity; Sampling strategy; Spatial autocorrelation analysis

\section{INTRODUCTION}

An appropriate sampling strategy is fundamental for the conserved samples that represent the total genetic diversity of a population or species. Therefore, for effective conservation to be accompanied by a proper strategy, the principle of strategic conservation is to capture the greatest diversity of a given population or species using the minimum number of samples. Two factors must be considered for strategic sampling - the number of samples, including the number of populations in a given area and the number of individuals within a given population, and the sampling methods in relation to the genetic structure of the populations under consideration (Jin and $\mathrm{Lu}, 2003$ ). Research on sampling strategies is fundamental for the collection of germplasm and for the conservation of biological diversity. Resources usually limit the species, populations, and individuals be sampled, and only a proportion of them can be collected and protected. However, samples should contain as much genetic variation as possible in order to reflect the evolutionary history of the species or populations. It is difficult to objectively assess the genetic diversity of a species being studied and protected without a reasonable sampling strategy to protect resources. Plant sampling strategy is affected by the plant's biological characteristics, environmental conditions, and the purpose of sampling (Gilbert et al., 1999; Li and Zeng, 2000; Zhu et al., 2006). Therefore, sampling strategies differ depending on the plant species, and suitable sampling strategies have been developed based on species' characteristics. Current research on plant sampling strategy has focused mainly on herbs (Ceska et al., 1997; Malosetti and Abadie, 2001; Li et al., 2003), with limited reports available for woody plants. A reasonable sampling strategy should include the following: the number of populations, by sampling a number of individuals within a population, and the distance between individuals. Therefore, it is important to understand the genetic diversity and spatial genetic structure of species that are being studied. Genetic diversity can reveal the level of genetic diversity and genetic differentiation among populations. Spatial genetic structure of natural populations is important for establishing sampling strategies (Mashall and Brown, 1975). The spatial genetic structure of genetic variation should be helpful to improve the efficiency of sampling, in order to capture more genetic diversity of species. Spatial autocorrelation analysis is an effective method used to study the spatial structure of genetic variation, especially in the context of small-scale areas, and can be used to detect and quantify spatial dependence for sampling values at calibration points (Sokal and Oden, 1978; Liu et al., 2008). Toona ciliata is a deciduous, broad-leaved, fast-growing tree species belonging to the Toona genus in Meliaceae. Flowers of this species are small, and pollen is dispersed mainly by the wind. This species is known as "Chinese mahogany", since the color of the wood is red, and the wood grain is very beautiful; therefore, T. ciliata is a valuable timber species with high economic value and development prospects (Liu et al., 2006; Zhang et al., 2006). Numbers of this species have declined due to environmental changes, logging, and its slow regeneration. The tree species is classified as second-class protection of endangered species in the Wildlife Conservation and Nature Reserve Management Department of the State Forestry

Genetics and Molecular Research 15 (4): gmr15047751 
Administration, Institute of Botany in Chinese Academy of Sciences (2013). It is also listed as a rare and endangered species throughout the provinces (Lou and Jin, 2000; Zhang, 2000; Liu and $\mathrm{Wu}, 2005)$. Therefore, genetic studies on the conservation of species diversity are urgent. Preliminary reports on the genetic diversity of this species include the genetic structure of natural populations (Liu et al., 2009), spatial genetic structure (Liu et al., 2008), and community structure (Liu et al., 2010). However, sampling strategies were not investigated in these studies, and no suitable sampling strategy was developed to conserve natural populations of T. ciliata. In view of this, materials collected in natural populations were used to analyze genetic diversity and spatial genetic structure with microsatellite loci. A reasonable sampling strategy in natural populations based on the results was developed, including the number of sampled populations, sampled individuals within populations, and the distance among sampled individuals. The study will guide the conservation of genetic diversity, germplasm collections, and preservation.

\section{MATERIAL AND METHODS}

\section{Materials}

Seven populations were surveyed in Zhejiang, Jiangxi, and Yunnan Provinces China in 2005 and 2006. Detailed information on the seven populations is listed in Table 1. Every individual was recorded using GPS positioning in the Yifeng population in Jiangxi Province. The distance between each individual was more than $50 \mathrm{~m}$. Upper leaves were collected from trees, separated, and dried rapidly with silica gel at a leaf mass ratio of 10:1.

Table 1. Geographic location and number of individuals sampled from seven natural populations of Toona ciliata.

\begin{tabular}{l|c|c|c|c|c}
\hline Population & Abbreviation & Longitude (E) & Latitude (N) & Altitude (m) & Individuals \\
\hline Yifeng & YF & $114^{\circ} 29^{\prime}-114^{\circ} 45^{\prime}$ & $28^{\circ} 30^{\prime}-28^{\circ} 40^{\prime}$ & $220-475$ & 65 \\
\hline Binchuan & BC & $100^{\circ} 16^{\prime}-101^{\circ} 23^{\prime}$ & $25^{\circ} 02^{\prime}-25^{\circ} 22^{\prime}$ & $1404-1820$ & 60 \\
\hline Yuanmou & YM & $101^{\circ} 49^{\prime}-101^{\circ} 52^{\prime}$ & $25^{\circ} 17^{\prime}-25^{\circ} 40^{\prime}$ & $1112-1230$ & 30 \\
\hline Wuding & WD & $102^{\circ} 08^{\prime}-102^{\circ} 12^{\prime}$ & $25^{\circ} 47^{\prime}-25^{\circ} 51^{\prime}$ & $1405-1802$ & 29 \\
\hline Shizong & SZ & $103^{\circ} 42^{\prime}-104^{\circ} 34^{\prime}$ & $24^{\circ} 21^{\prime}-25^{\circ} 00^{\prime}$ & $812-912$ & 84 \\
\hline Xianju & XJ & $120^{\circ} 32^{\prime}-120^{\circ} 56^{\prime}$ & $28^{\circ} 48^{\prime}-28^{\circ} 56^{\prime}$ & $600-820$ & 27 \\
\hline Suichang & SC & $119^{\circ} 12^{\prime}-119^{\circ} 23^{\prime}$ & $28^{\circ} 30^{\prime}-28^{\circ} 36^{\prime}$ & $510-1220$ & 25 \\
\hline
\end{tabular}

\section{Genomic DNA extraction and PCR amplification}

Genomic DNA was extracted using a modified CTAB (cetyltrimethyl ammonium bromide) method (Doyle, 1991; Liu et al., 2006). SSR (simple sequence repeat marker) primers were designed and selected in our lab, and eight polymorphic primer pairs, which gave reproducible, clear, and stable amplified bands, were used (Liu et al., 2006). The reaction system, PCR procedures, gel electrophoresis, and silver staining methods were performed as previously described (Liu et al., 2009).

\section{Data analysis}

Genetic diversity parameters were estimated using the POPGENE version 1.31 software. The following parameters were estimated to determine population-level variation: alleles $\left(N_{\mathrm{A}}\right)$, effective number of alleles $\left(N_{\mathrm{E}}\right)$, observed heterozygosity $\left(H_{\mathrm{O}}\right)$, expected 
heterozygosity $\left(H_{\mathrm{E}}\right)$, and genetic differentiation coefficient $\left(F_{\mathrm{ST}}\right)$. A total of $5,10,15,30,45$, and 65 individuals were randomly selected, and this was repeated four times to obtain data for PopGen32 analysis in order to detect how the number of individuals sampled number affects genetic diversity in Yifeng population. Genetic diversity parameters were calculated with different sampling numbers. Spatial autocorrelation analysis was performed as described by Chen (2001) and Liu et al. (2008).

\section{RESULTS}

\section{Number of sampled populations based on analysis of genetic diversity}

Locus Tc06 and Tc07 have eight alleles, and locus Tc02 has four alleles. The average $N_{\mathrm{A}}$ was 6.1. $N_{\mathrm{E}}$ ranged from 1.4 to 3.6, the average $N_{\mathrm{E}}$ was 2.7 . The average $H_{\mathrm{O}}$ was 0.6275 , which ranged from 0.3344 to 0.8656 (Table 2). The average $H_{\mathrm{E}}$ was 0.6006 , ranging from 0.2922 to 0.7199 . The average $F_{\mathrm{ST}}$ was 0.1854 , ranging from 0.631 to 0.4192 , which indicates that $81.46 \%$ of the genetic variation occurs within populations and $18.54 \%$ occurs between populations.

Table 2. Genetic diversity of Toona ciliata.

\begin{tabular}{l|c|c|c|c|c|c}
\hline Locus & $N_{\mathrm{A}}$ & $N_{\mathrm{E}}$ & $F_{\mathrm{IS}}$ & $F_{\mathrm{ST}}$ & $H_{\mathrm{E}}$ & $H_{\mathrm{O}}$ \\
\hline $\mathrm{Tc} 01$ & 5 & 2.7 & -0.1389 & 0.2690 & 0.6299 & 0.5969 \\
\hline $\mathrm{Tc} 02$ & 4 & 1.4 & -0.3401 & 0.1149 & 0.2922 & 0.3344 \\
\hline $\mathrm{Tc} 03$ & 6 & 2.0 & -0.0975 & 0.0631 & 0.5080 & 0.5375 \\
\hline $\mathrm{Tc} 04$ & 7 & 2.9 & -0.5791 & 0.1830 & 0.6605 & 0.8656 \\
\hline $\mathrm{Tc} 05$ & 6 & 3.3 & -0.4900 & 0.4192 & 0.6968 & 0.6020 \\
\hline $\mathrm{Tc} 06$ & 8 & 3.5 & -0.2628 & 0.1025 & 0.7145 & 0.8065 \\
\hline $\mathrm{Tc} 07$ & 8 & 3.6 & 0.1396 & 0.0631 & 0.7199 & 0.6187 \\
\hline $\mathrm{Tc} 08$ & 5 & 2.4 & -0.4074 & 0.2131 & 0.5826 & 0.6586 \\
\hline Average & 6.1 & 2.7 & -0.2479 & 0.1854 & 0.6006 & 0.6275 \\
\hline Standard Deviation & 1.4577 & 0.7667 & 0.2337 & 0.1217 & 0.1439 & 0.1627 \\
\hline
\end{tabular}

$N_{\mathrm{A}}$ : allele number; $N_{\mathrm{E}}$ : effective allele number; $F_{\mathrm{IS}}:$ inbreeding coefficient; $F_{\mathrm{ST}}:$ genetic divergence coefficient; $H_{\mathrm{E}}$ : expected heterozygosity; $H_{\mathrm{O}}$ : observed homozygosity.

The number of sampled populations was estimated with the coefficient of gene differentiation according to the method described by Hamrick et al. (1991). If the number of sampled populations is $\mathrm{n}$, the genetic variation contained in these populations is $1-\left(F_{\mathrm{ST}}\right)$ n. The average coefficient of gene differentiation among populations was 0.1854 ; therefore $96.6 \%$ variance occurred in two populations of species in this study. Therefore, populations with higher levels of genetic diversity can be sampled from the natural population. Seven populations were clustered using UPGMA (unweighted pair-group method with arithmetic means) (Figure 1) according to Nei's (1978) genetic distance between seven populations. Three populations from Yifeng, Xianju, and Suichang (SC) from northern areas clustered together, while four populations from Yuanmou (YM), Binchuan, Wuding, and Shizong from the southern area clustered together in the dendrogram. Thus, two populations should be selected, one from the northern area, and one from the southern area. Populations SC and YM were suitable for sampling and protection.

\section{Effects of sampling number on genetic diversity}

To determine values for genetic diversity parameters, samples of $5,10,15,30,45$, 
and 65 individuals were analyzed. The $N_{\mathrm{E}}$ and $H_{\mathrm{E}}$ are shown in Tables 3 and 4 . The mean $N_{\mathrm{E}}$ increased significantly with sampling number (Table 3 ). When the number of plant samples was five, the $N_{\mathrm{E}}$ was 1.6927. When the sampling number was 65 , the $N_{\mathrm{E}}$ was 2.0753 . $H_{\mathrm{E}}$ with different numbers of samples is shown in Table 4 . The $H_{\mathrm{E}}$ was 0.3987 when the sample number was five. $H_{\mathrm{E}}$ also increased with increasing sample number and stabilized between 0.4641 and 0.4770 when the sample number increased to 30 individuals. When the sampling number was $45, H_{\mathrm{E}}$ was at the maximum observed level of 0.4770 . In summary, the number of samples for each population should exceed 30 individuals, with 45 samples per population being the most appropriate number to ensure genetic protection when natural populations are sampled.

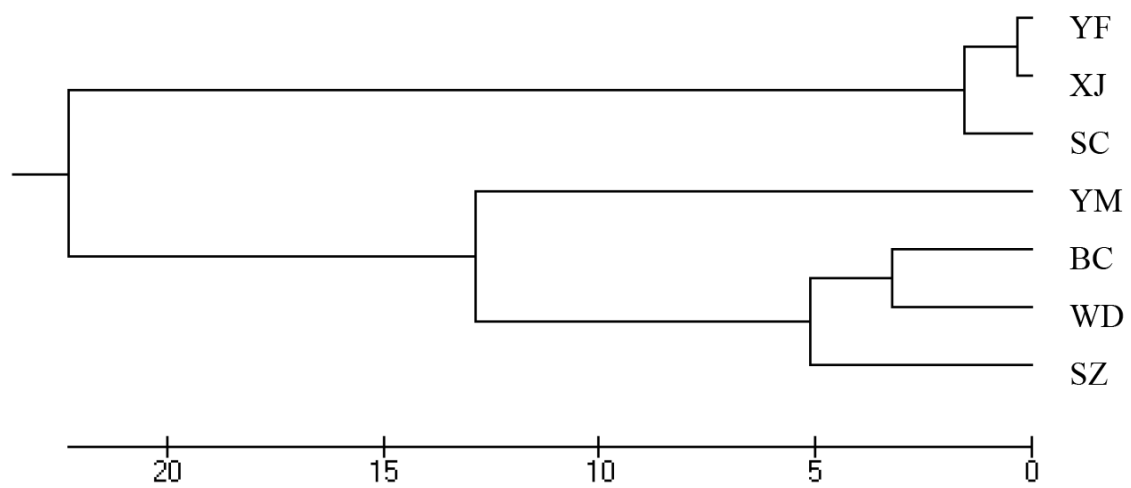

Figure 1. UPGMA clustering according to Nei's (1978) genetic distance for seven populations. $\mathrm{YF}=\mathrm{Yifeng}, \mathrm{XJ}=$ Xianju, $\mathrm{SC}=$ Suichang, $\mathrm{YM}=$ Yuanmou, $\mathrm{BC}=$ Binchuan, $\mathrm{WD}=$ Wuding, and $\mathrm{SZ}=$ Shizong.

Table 3. Effect of sampling number on the number of effective alleles.

\begin{tabular}{l|c|c|c|c|c}
\hline \multirow{2}{*}{ Sampling number } & \multicolumn{3}{|c|}{ Replication } & \multirow{2}{*}{ Mean } \\
\cline { 2 - 6 } & 1 & 2 & 3 & 1.6377 & 1.9388 \\
\hline 5 & 1.6070 & 1.5871 & 1.7644 & 1.7915 & 1.6927 \\
\hline 10 & 1.7106 & 1.7233 & 1.7901 & 2.0172 & 1.7678 \\
\hline 15 & 1.8537 & 1.8322 & 1.9037 & 2.0363 & 1.9688 \\
\hline 30 & 2.0375 & 1.9167 & 2.0520 & 2.0753 & 2.0248 \\
\hline 45 & 1.9939 & 2.0170 & 2.0753 & & 2.0753 \\
\hline 65 & 2.0753 & 2.0753 & &
\end{tabular}

Table 4. Effect of sampling number on expected heterozygosity.

\begin{tabular}{l|c|c|c|c|c}
\hline \multirow{2}{*}{ Sampling number } & \multicolumn{3}{|c|}{ Replication } & \multirow{2}{*}{ Mean } \\
\cline { 2 - 6 } & 1 & 2 & 3 & 0.4163 & 0.4975 \\
\hline 5 & 0.3248 & 0.3562 & 0.4224 & 0.4392 & 0.4216 \\
\hline 10 & 0.3803 & 0.4216 & 0.4224 & 0.4960 & 0.4220 \\
\hline 15 & 0.4113 & 0.4328 & 0.4480 & 0.4808 & 0.4641 \\
\hline 30 & 0.4506 & 0.4616 & 0.4903 & 0.4680 & 0.4770 \\
\hline 45 & 0.4606 & 0.4680 & 0.4680 & 0 \\
\hline 65 & 0.4680 & & &
\end{tabular}

Genetics and Molecular Research 15 (4): gmr15047751 


\section{Spatial autocorrelation analysis to determine the distance between sampled individuals}

Genetic variation within plant populations follows a patchy distribution rather than a completely random distribution, resulting in a spatial pattern determined by differences in the plant microenvironment between populations, plant breeding system, and the mechanism of seed and pollen transmission. Correlation coefficients were calculated between individuals in the Yifeng population, the distance between individuals was divided into eight levels, with each level being equal to $80 \mathrm{~m}$. Results of the autocorrelation analysis are shown in Figure 2 and show that the spatial autocorrelation coefficient was a significant positive correlation when individuals were spaced within $240 \mathrm{~m}$ in Yifeng population. These results indicated that individuals located within $240 \mathrm{~m}$ in the Yifeng population were similar. The negative values were greater than the positive values, with the values increasing when the distance between individuals exceeded $240 \mathrm{~m}$, which indicates that individuals differ greatly when the distance between them exceeds $240 \mathrm{~m}$. Therefore, the distance between individual trees should exceed $240 \mathrm{~m}$ within populations during sampling in order to avoid duplication of sampling.

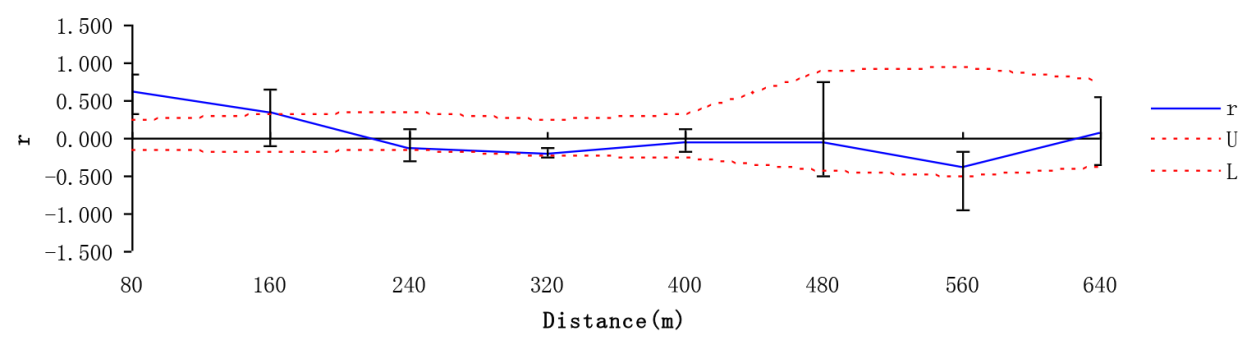

Figure 2. Spatial autocorrelation analysis of Toona ciliata population. r: spatial correlation coefficient; U, L: upper and lower error bars with $95 \%$ confidence interval, respectively.

\section{DISCUSSION}

Genetic diversity parameters for seven populations of $T$. ciliata in China were analyzed with eight SSR markers. The average $N_{\mathrm{A}}$ for seven populations was 3.375 , the average $N_{\mathrm{E}}$ was 2.0753 , and the average $H_{\mathrm{E}}$ was 0.492 . The population genetic differentiation coefficient was 0.112 . Two natural populations of the species accounted for $98.7 \%$ of the total variance according to the genetic differentiation coefficient. Therefore, two populations with a high level of genetic diversity were selected in order to sample natural populations to ensure their genetic protection. The results of this study are similar to those reported previously for Baptisia arachnifera (Ceska et al., 1997).

The mean $N_{\mathrm{E}}$ and expected heterozygosity increased significantly with sampling number. The $H_{\mathrm{E}}$ stabilized between 0.4641 and 0.4770 when 30 individuals were sampled. When the number of individuals sampled was 45 , the value for $H_{\mathrm{E}}$ was the highest at 0.4770 . Therefore, when sampling in natural populations or for protection, the number of individuals sampled from each population should exceed 30 , and 45 samples per population is the most appropriate number. Zhu et al. (2006) and Jin et al. (2003) found that the sampling number was 27-52 when natural populations of wild soybean were sampled; this sampling number provides good results for captured the large proportion of population genetic diversity.

Genetics and Molecular Research 15 (4): gmr15047751 
We found that individuals from the Yifeng population were similar when the distance between them was less $240 \mathrm{~m}$ by spatial autocorrelation analysis. Individuals varied greatly when the distance exceeded $240 \mathrm{~m}$ in the population. Therefore, the distance between individual trees should be more than $240 \mathrm{~m}$ when sampling within populations in order to ensure the collection of completely different genotypes. This will result in more genetic diversity being obtained for the same sampling number. The results of the present study are different to those obtained with herbal soybean (Zhu et al., 2006) and Cyclobalanopsis glauca (Chen, 2001). This difference may have occurred because of the biological characteristics of different species. T. ciliata has a small flower, and its pollen is mainly dispersed by the wind. The fruit is a capsule, which cracks naturally when mature. Its seeds have membranous wings, and are transmitted mainly by the wind meaning that the seeds can be transmitted over long distances. Soybean and $C$. glauca fruits are heavier than those of T. ciliata, and will be transmitted by animals and gravity over a relatively limited distance.

\section{Conflicts of interest}

The authors declare no conflict of interest.

\section{ACKNOWLEDGMENTS}

Research supported by the Forestry Public Welfare Industry Research (\#201204307) and the National Natural Science Foundation of China (\#31570658).

\section{REFERENCES}

Ceska JF, Affolter JM and Hamrick JC (1997). Developing a sampling strategy for Baptisia arachnifera based on allozyme diversity. Conserv. Biol. 11: 1133-1139. http://dx.doi.org/10.1046/j.1523-1739.1997.95527.x

Chen XY (2001). Spatial autocorrelation of genetic structure in a population of Cyclobalanopsis Glauca in Huanshan, Anhui. Acta Phytoecol. Sin. 25: 29-34.

Doyle J (1991). DNA protocols for plants CTAB total DNA isolation. In: Molecular Techniques in Taxonomy (Hewitt GM and Johnston A, eds.). Springer, Berlin, 283-293.

Gilbert JE, Lewis RV, Wilkinson MJ and Caligari PDS (1999). Developing an appropriate strategy to assess genetic variability in plant germplasm collections. Theor. Appl. Genet. 98: 1125-1131. http://dx.doi.org/10.1007/ $\underline{\mathrm{s} 001220051176}$

Hamrick JL, Godt MJW, Murawski DA and Loveless MD (1991). Correlation between species traits and allozyme diversity: implication for conservation biology. In: Genetics and conservation of rare plants (Falk DA and Holsinger KE, eds.). Oxford University Press, New York.

Jin Y and Lu BR (2003). Sampling strategy for genetic diversity. Biod. Sci 11: 155-161.

Jin Y, He T and Lu BR (2003). Fine scale genetic structure in a wild soybean (Glycine soja) population and the implications for conservation. New Phytol. 159: 513-519. http://dx.doi.org/10.1046/j.1469-8137.2003.00824.x

Li Y, Wang TY, Tian SJ, Shi YS, et al. (2003). Sampling strategies of maize populations when molecular markers are used in genetic diversity analysis. Plant Genet. Resour. 4: 314-317.

Li ZC and Zeng YW (2000). Study on sampling schemes of core collection of local varieties of rice in Yunnan, China. Zhongguo Nong Ye Ke Xue 33: 1-7.

Liu J, Sun ZX, Chen YT, He GP, et al. (2006). Isolation of microsatellite DNA from endangered tree Toona ciliata var. pubescens and optimization of SSR reaction system. China Biotechnol. 26: 50-55.

Liu J, Chen YT, Jiang JM, He GP, et al. (2009). Study on population genetic structure in Toona ciliata var. pubescens. For. Res. 22: 37-41.

Liu J, Chen YT, Jiang JM and Shao WH (2010). Study on community characters of Toona ciliata var. pubescens natural Forest. For. Res. 23: 93-97.

Genetics and Molecular Research 15 (4): gmr15047751 
Liu J, Chen YT, Sun ZX, Jiang JM, et al. (2008). Spatial genetic structure of Toona ciliata var. pubescens populations in terms of spatial autocorrelation analysis. Sci. Silvae Sin. 44: 45-52.

Liu XZ and Wu HP (2005). Scientific investigation and research of Guanshan nature reserve in Jiangxi province. China Forest. Publishing House 118-120.

Lou HH and Jin SH (2000). Spermatophyta flora of Gutianshan nature reserve in Zhejiang. J. Beijing Forest. Univ. 22: 33-39.

Malosetti M and Abadie T (2001). Sampling strategy to develop a core collection of Uruguayan maize landraces based on morphological traits. Genet. Resour. Crop Evol. 48: 381-390. http://dx.doi.org/10.1023/A:1012003611371

Mashall DR and Brown ADH (1975). Crop genetic recourses for today and tomorrow. Cambridge: Cambridge University Press.

Nei M (1978). Estimation of average heterozygosity and genetic distance from a small number of individuals. Genetics 89: 583-590.

Sokal RR and Oden NL (1978). Spatial autocorrelation in biology, 1. Methodology. Biol. J. Linn. Soc. Lond. 10: 19-228. http://dx.doi.org/10.1111/j.1095-8312.1978.tb00013.x

Wildlife Conservation and Nature Reserve Management Department of the State Forestry Administration, Institute of Botany in Chinese Academy of Sciences (2013). Rare and endangered plant in China. China Forestry Publishing House, 247.

Zhang GF (2000). Study on rare and threatened plants of Anhui and their conservation. J. Anhui Normal Univ. 23: 36-39.

Zhang L, Guo LH and Du TZ (2006). The effects of shading and soil water content on photosynthesis of Toona ciliata var. pubescens seedlings. J. Nanjing Forestry Univ. 30: 63-66.

Zhu WY, Zhou TY, Zhong M and Lu BR (2006). Sampling strategy for wild soybean (Glycine soja) populations based on their genetic diversity and fine-scale spatial genetic structure. J. Fudan Univ. 45: 321-327.

Genetics and Molecular Research 15 (4): gmr15047751 